\title{
Hybrid venture capital fundraising in emerging markets: A pitch
}

\author{
Martin Jurek ${ }^{\mathrm{a}, 1}$ \\ ${ }^{a}$ University of Economics, Prague, Czech Republic
}

\begin{abstract}
This paper applies the pitch template developed by Faff (2017) for an academic research topic in venture capital finance, with a focus on government fundraising in Central and Eastern European countries. The template summarizes the key elements forming the structure of any research proposal. After an introduction and brief commentary on the pitch, a personal reflection on the "process of research in business course" experience is presented.
\end{abstract}

Keywords: Pitching research; Venture capital; Private equity, Government funds, Central and Eastern European countries

\section{JEL codes: M48, G24}

\section{Introduction}

This paper is a descriptive analysis of a so called pitch template, as well as its application and includes a personal reflection on an experience from professor Faff's 3-day course titled "The Process of Research in Business," where this concept was first introduced to the author. The "pitch concept" is derived from Faff (2017) which is a follow up on Faff (2015). In this paper, the application on an academic research topic in venture capital finance is presented.

Regarding my scholarly background, I already received my $\mathrm{PhD}$ degree in 2014, but started to work as a full time assistant professor at the University of Economics in Prague in just this academic year. Upon reflection, while studying for my $\mathrm{PhD}$ degree, it may be needless to admit that my research activity was not very abundant. Using Stokes (2013) description, the adverse factors for my rather

${ }^{1}$ Corresponding author: Martin Jurek, Department of International Business, University of Economics, Prague; W. Churchill Sq. 1938/4, 13067 Prague 3 - Zizkov, Czech Republic; tel. (+420) 775691601 ; email address: martin.jurek@vse.cz 
mediocre research performance were both the opportunity and approach conditions. ${ }^{1}$ Especially the lack of patronage and no research team to be part of were my main hindrances.

Further, according to Sutton and Brown (2012, cited in Stokes, 2013) I could identify myself with the "idealist" researcher - valuing more the outcomes and contributions of one's research. ${ }^{2}$ As a result of the background described above, my position of a novice researcher was very suitable for "The Process of Research in Business" course and I took the invitation to attend Professor Faff's seminars with great pleasure.

The remainder of this paper is structured in the following way: Section 2 gives a brief commentary on the pitch. Section 3 then provides my personal reflections on the "pitch concept" and related relevant comments on Professor Faff's 3-day course, "The Process of Research in Business". The last section concludes.

\section{Brief commentary on the pitch}

The first draft of the pitch was completed in April 2017 and submitted as part of the pre-course homework exercise to the "The Process of Research in Business" course. The estimated time spent on it exceeded one working day - excluding literature review. This initial pitch was presented to professor Faff during the 3-day course. Consistent with the Faff (2017) expectations of a pitch evolvement, the very first version was rough, raw and incomplete. Receiving very valuable feedback and discussing diverse elements, the pitch was revised, important aspects reconsidered and most of the comments applied. The final version of the pitch on determinants of venture capital activity, with its focus on government support in Central and Eastern European countries is shown in Table 1.

According to Faff (2017), this pitch is classified as a "real" and an "owned" pitch and relates to a research topic that I am currently progressing. The basic research question captured is: How do government funds drive the venture capital activity in Central and Eastern European countries? The selection of foundational papers follows the three rules of thumb approach ${ }^{3}$. Dias and Macedo (2016) identify six main drivers of the demand and supply of venture capital funds through factor analysis. Groh and Liechtenstein (2011) examine the diverse limited partnerships operating in Central and Eastern European countries and identify funds allocation determinants. Overall current tendencies of venture capital in emerging markets (including thus also, Central and Eastern European countries) are introduced by Lerner et al. (2016).

The motivation for this research topic emanates not only from academic literature itself, but is also linked to an actual market pattern. Government investment funds 
have appeared in many developed European venture capital markets during past twenty years. Following this trend, investment funds with government support have already been launched in some and will begin in other Central and Eastern European countries (e.g. in the Czech Republic in late 2017). Is the economic rationale based on the so called equity gap on the supply side sufficient? Is the venture capital activity not hindered rather by the demand side factors?

The pitch continues with the core of the template built around a "3-2-1" design, following Faff (2013). The "three" represents essential elements of the Idea, the Data and the Tools. The "Idea" part elaborates further on the initial research question: How do determinants of VC activity influence the investment activity in emerging countries? Is the lack of government support the main driver of imbalance between the venture capital supply and demand? Are the differences decisive when justifying such financial support? Factor analysis applied with its dependent/independent variables and description of data is displayed in Table 1.

More specifically, the panel data methodology is employed, as data on crosssectional time series is available. It allows us to control for the effects of variables that specifically affect the dependent variable of each country (individual heterogeneity). The econometric method for our regression model is a generalized least square estimation. To test the presence of autocorrelation in the residuals of our regression equations, the Durbin-Watson statistic is used. The potential endogeneity is tested by the Hausman test.

The "two" presents answers to the two key questions: What's new? So what? To our knowledge, the currently important role of government funding of venture capital in some emerging markets has not yet been thoroughly investigated. The insufficient venture capital supply has been identified as a main driver of venture capital market performance in Western European countries (Kraemer-Eis et al., 2016). Such imbalances between demand and supply can be more pronounced in growing emerging markets. It might be estimated that, for the case of emerging markets, the determinant of government support is thus recommended to be added to the six key parameters shaping national venture capital as presented by earlier studies (e.g. Groh \& Liechtenstein, 2011).

According to Lerner (2002), the theory of public finance mentions that any public support can be an appropriate response in relation to activities that generate positive externalities. If this was not the case of the venture capital support, the crowding out effect could, on the contrary, deteriorate the venture capital in emerging markets.

The "one" is describing the number one goal - the contribution of the research. The primary source of the contribution is researching venture capital activity in Central and Eastern Europe with a focus on the actual importance of government support in the venture capital emerging markets. 
Table 1. Completed 2-page pitch template on an 'academic research topic in venture capital finance'

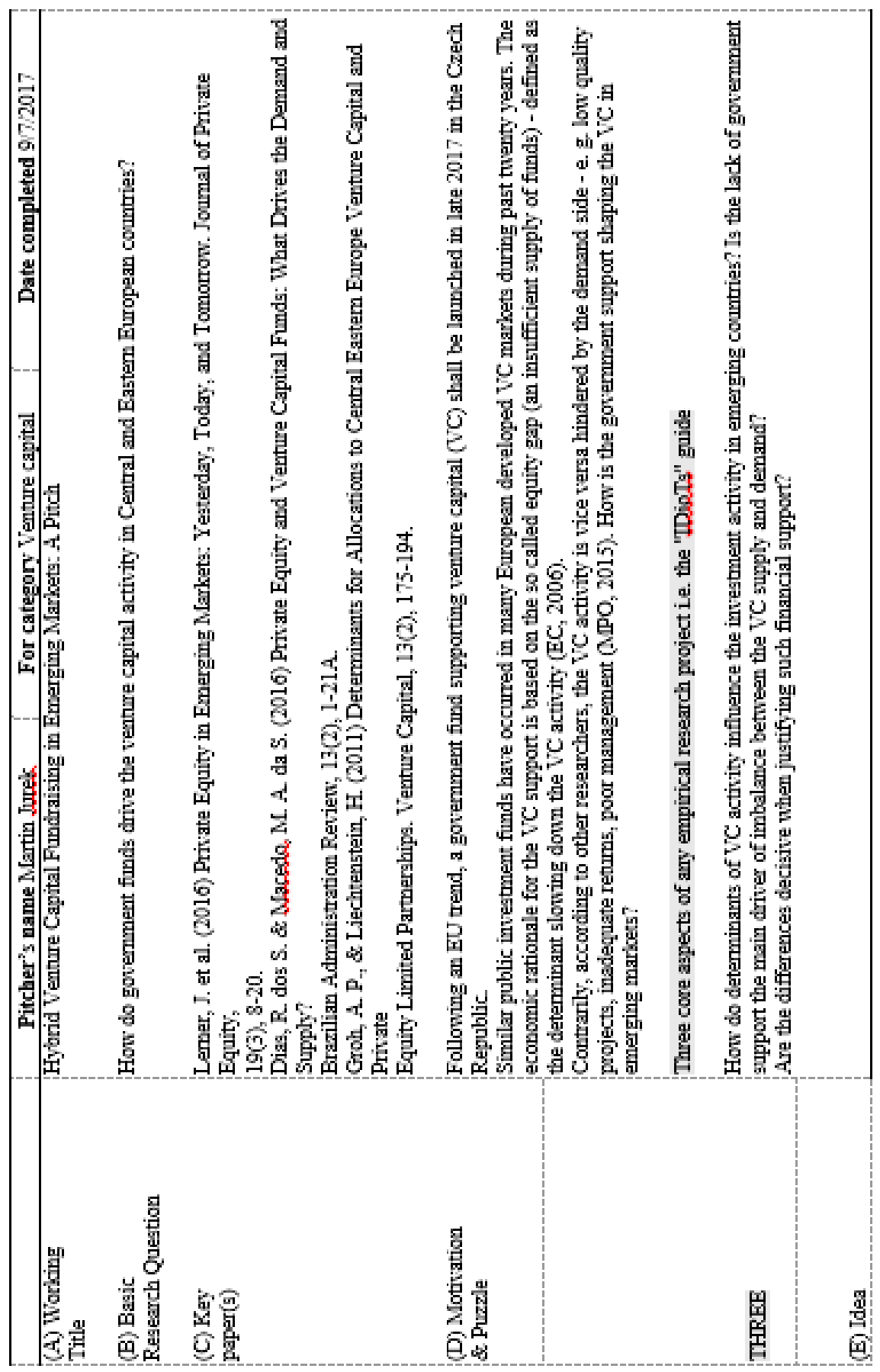




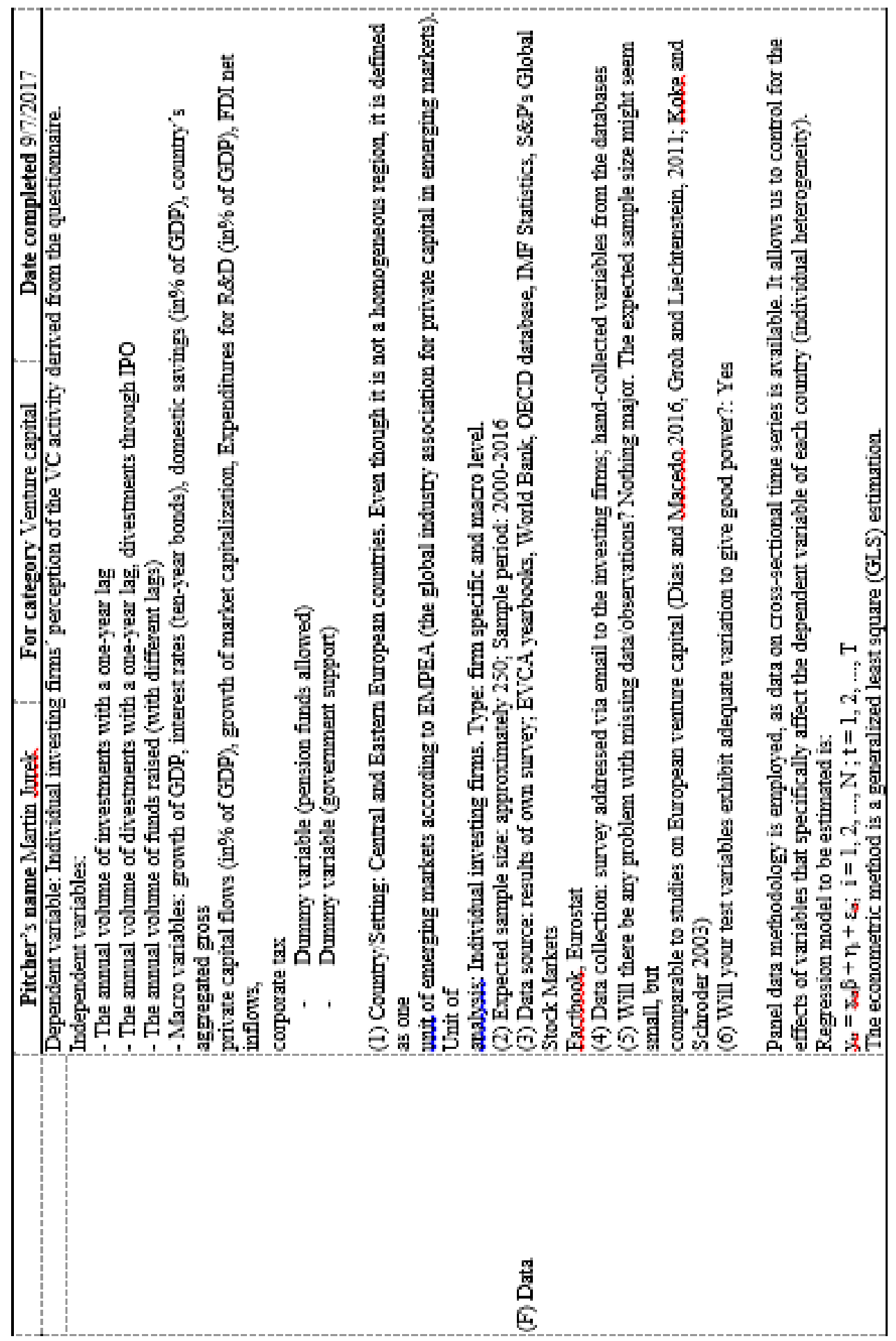

Vol. 17, No. 1 


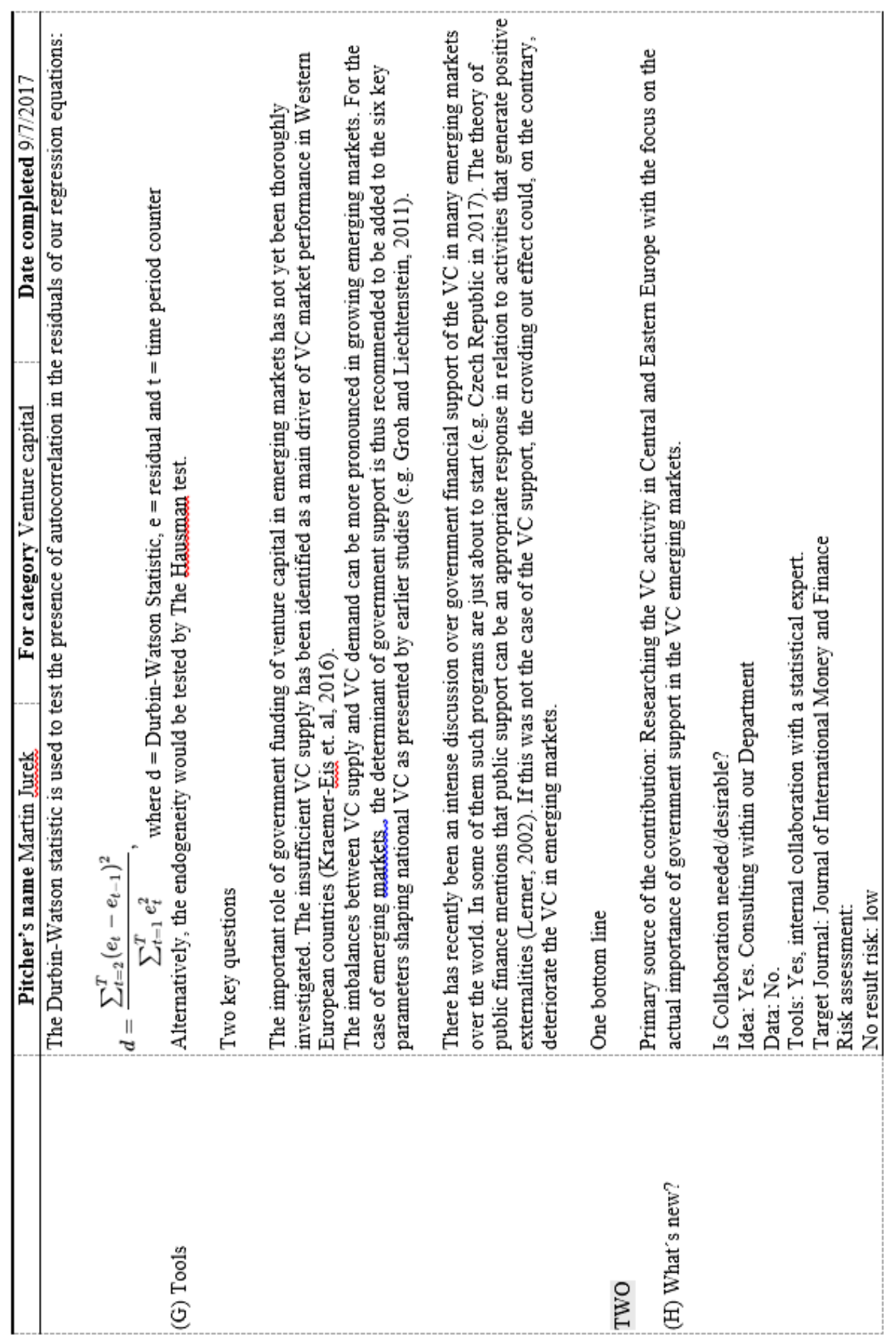




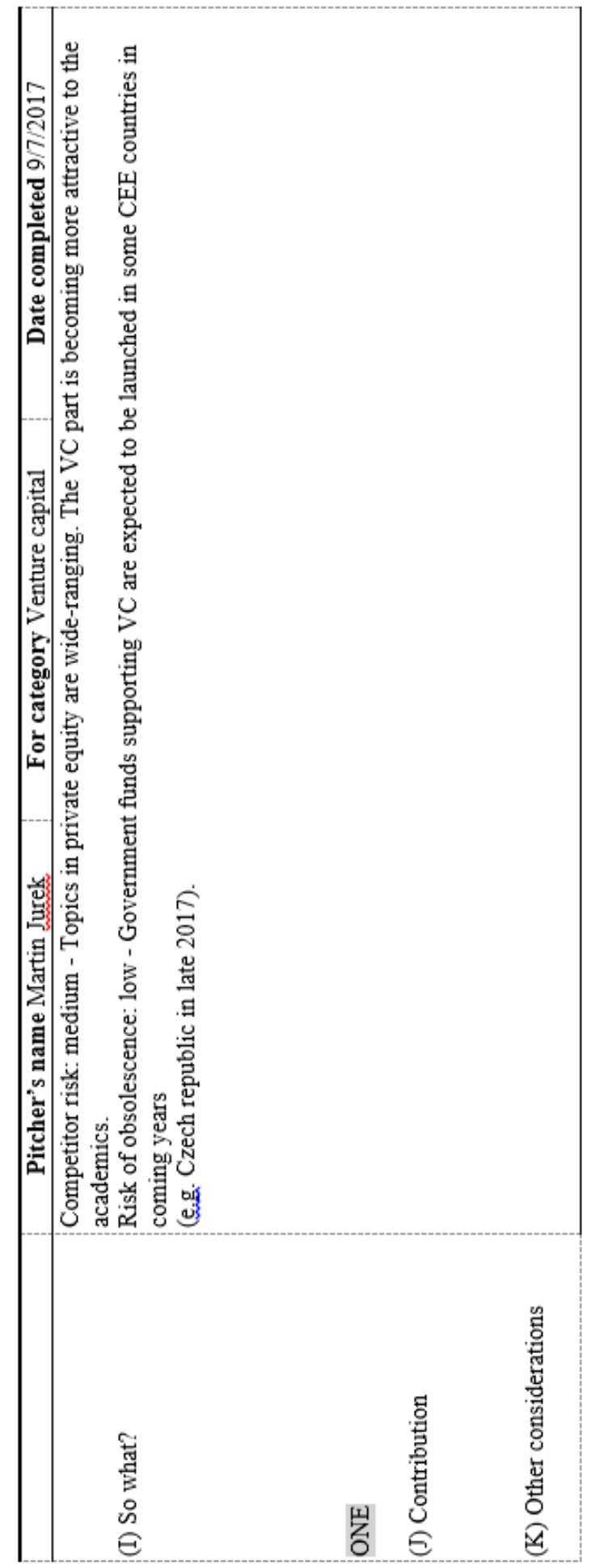

Vol. 17, No. 1 


\section{Personal reflections on the pitch exercise}

Ratiu (2015) confirms that "starting" is the major challenge when doing research. In accordance with my short academic experience, I would dare to add that the biggest hurdle is to know how to start. In this respect, the pitching template is an excellent "know-how" tool to any $\mathrm{PhD}$ students or novice researchers. This tool not only directly guides through the preliminary phases of any research proposal, but also provides its user a great evaluation mechanism to any research ideas. The concise layout of the template particularly helps manage all thoughts in an effective way.

The pitching task is best thought of as a dynamic and iterative process, in which the "path" to a completed pitch is non-linear and unpredictable (Faff, 2017). According to my experience, out of the eleven elements characterizing the pitch template, the idea, contribution, motivation and data were the four most time consuming. As far as linearity is concerned, Faff (2017) evaluates its degree based on a user's behavior on the PitchMyResearch.com. web portal.

A caution here is suggested as, in my case, this approach would not reflect reality. I indeed have proceeded in a non-linear way to use the copied pitch template into a text document. However, when completing the template online, I copied and pasted all the individual parts of the template from the text document, from the top to the bottom. The web portal would have thus captured and reported my behavior as strictly linear.

Unda (2015) expresses her fascination over the use of the "Mickey Mouse" diagram to illustrate a triple intersection of research attention in connection to her childhood memories of this cartoon character. My admiration of the triple Venn diagram depicted in one's clarification of the contribution of research to current literature. And as Faff (2017) suggests, answers to the two questions: "What's new?" and "So what?" is the "holy grail" of any research.

Kiley and Wisker (2009) also confirm that many $\mathrm{PhD}$ graduates are unable to explain why or how it was that their research was significant or important identifying the "So what?" factor of the research. The "Mickey Mouse" diagram, applied to my pitch displayed in Figure 1, helped to stimulate my thinking toward "innovation" rather than "invention". As Faff (2013) highlights, as novice researcher I also at first fell for the "trap" of taking a very literal interpretation of the word "new", when starting my "new" research. With guidance from the "Mickey Mouse" diagram I clarified the "innovation" of my research that might deliver reasonably influential outcomes. I agree with Beaumont's (2015) expression about the "other considerations" section. Considering target journals and examining the "risks" of competitors and of obsolescence have earlier not much attracted my attention. 


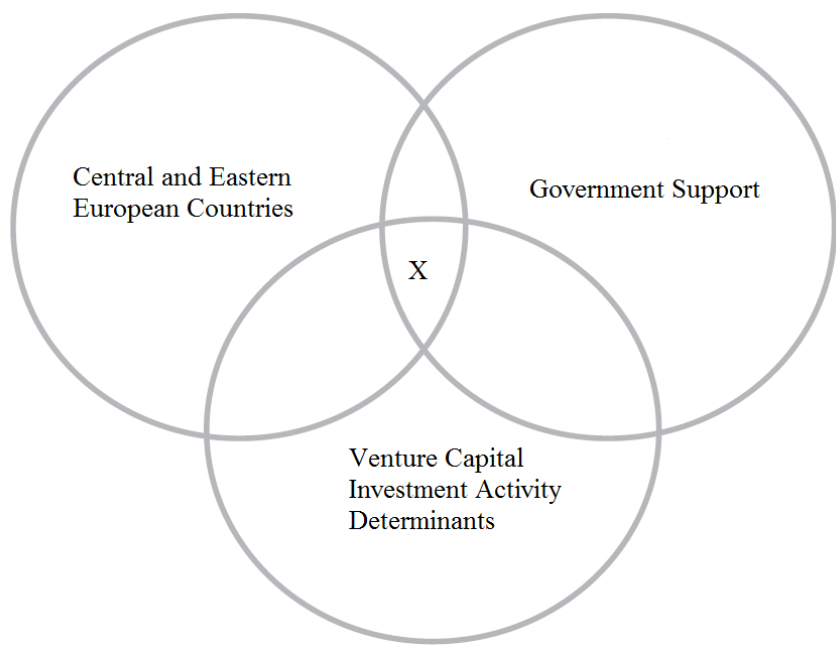

\section{Figure 1. Mickey Mouse diagram applied to the pitch characterizing novelty of the research idea}

"The Process of Research in Business" course helped me to clarify the importance of distinguishing between a primarily scholarly or industry oriented research - i.e. to orient one's research toward relevant stakeholders. The important fact is that the pitching concept, with its adjustments, is applicable to the often more challenging non-academic engagement and impact of a proposed new research project, while maintaining its goal to achieve quality academic output (Faff, 2016).

The key take away from the course is the view of one's academic career. Professor Faff emphasized the crucial importance of a research mindset, and research's priority over teaching, supervising and administrative commitments. Otherwise, the research becomes a residual activity. The decision to be a scholarly valuable researcher is thus sometimes an ongoing process of "forcing" one's will, resulting in a so called "forced research". This is a term that has its origin in the "forced saving" concept. ${ }^{4}$

Other aspects to consider were the understanding of the work of editors/referees and the clarity and scale of one's research focus with an accent on avoidance of "massive jumps" in topics covered. Lastly, professor Faff has drawn my attention to the "Matthew effect" in research - an accumulative advantage that research success entails - as the Sutton and Brown (2012, cited in Stokes, 2013) finding confirms: If a researcher values doing the research, then he/she exerts more effort to produce the recognized innovation outcomes. The benefit in doing so is less about extrinsic financial rewards, but more about gaining rewards by way of more resources, including time for the research and to pursue the passion. ${ }^{5}$ 


\section{Conclusion}

This paper primarily provides an application of the pitch template to the topic covering determinants of venture capital activity in Central and Eastern European countries, with its focus on government financial support.

This pitch is an improvement of its initial version, revised in accordance with professor Faff's feedback. It has been constructed in the middle stage of the research - at the data analysis phase. The pitching template is an excellent "knowhow" tool for any $\mathrm{PhD}$ students or novice researchers, not only when starting but also in later stages of research. Besides its structure and concise layout, it draws researcher's attention to the key element of any scholarly career - to the contribution of one's research to the current state of knowledge.

Secondarily, in this paper, a short reflection on an experience from professor Faff's 3-day course called "The Process of Research in Business" is outlined. Here the forced research concept is mainly discussed. Overall I am grateful for the introduction to the pitch template and it will surely be a main tool to apply in future researches.

\section{References}

Beaumont, S. (2015) "An investigation of the short and long run relations between executive cash bonus payments and firm financial performance: a pitch", Accounting \& Finance 55: 337-343

Dias, R. dos S. \& Macedo, M. A. da S. (2016) "Private equity and venture capital funds: what drives the demand and supply?", Brazilian Administration Review, 13(2): 1-21A

EC (2006) "Report of the alternative investment expert group. Developing European private equity", Available at: http://ec.europa.eu/internal_market /investment/docs/other_docs/reports/equity_en.pdf

Faff, R. (2017) "Pitching Research ${ }^{\circledR}$ ", Available at SSRN: http://ssrn.com/abstract=2462059 or http://dx.doi.org/10.2139/ssrn.2462059 [latest version]

Faff, R.W. \& Kastelle, T. (2016), "Pitching research for engagement and impact" (July 22, 2016). Available at SSRN: http://ssrn.com/abstract=2813096 or http://dx.doi.org/10.2139/ssrn.2813096

Faff, R. (2015) "A simple template for pitching research", Accounting and Finance, 55: 311-336

Faff, R. (2013) "Mickey Mouse and the IDioT Principle for Assessing Research Contribution: Discussion of 'Is the Relationship between Investment and Conditional Cash Flow Volatility Ambiguous, Asymmetric or both?"', Accounting and Finance, 53: 949-960 
Groh, A. P. \& Liechtenstein, H. (2011) „Determinants for allocations to central eastern europe venture capital and private equity limited partnerships", Venture Capital, 13(2): 175-194

Kiley, M. \& Wisker, G. (2009) "Threshold concepts in research education and evidence of threshold crossing", Higher Education Research \& Development, 28(4): 431-441

Koke, J. \& Schroder, M. (2003) "The prospects of capital markets in Central and Eastern Europe", Eastern European Economics, 41(4): 5-37

Kraemer-Eis, H., Signore, S. \& Prencipe, D. (2016) "The European venture capital landscape: an EIF perspective, EIF Research \& Market Analysis Working Paper 2016/34

Lerner, J., Ledbetter, J., Speen, A., Leamon, A. \& Allen, C. (2016) "Private equity in emerging markets: yesterday, today, and tomorrow", Journal of Private Equity, 19(3): 8-20

Lerner, J. (2002) "When bureaucrats meet entrepreneurs: the design of effective 'public venture capital' programmes", The Economic Journal 112: 73-84

MPO (2015) "Národní inovační fond - studie proveditelnosti“, Available at: http://www.komora.cz/pro-podnikani/legislativa-a-normy/pripominkovanilegislativy/nove-materialy-k-pripominkam/140-15-narodni-inovacni-fondstudie-proveditelnosti-t-21-7-2015.aspx

Ratiu, R.V. (2015) "Financial reporting of European banks during the GFC: A pitch", Accounting \& Finance 55: 345-352

Stokes, D. (2013) "Generating innovative research ideas", Accounting and Management Information Systems, 12(2): 145-155

Unda, L.A. (2015) "Board of directors characteristics and credit union financial performance: a pitch", Accounting \& Finance 55: 353-360

Kiley, M. \& Wisker, G. (2009) "Threshold concepts in research education and evidence of threshold crossing", Higher Education Research \& Development, 28(4): 431-441

${ }^{1}$ Stokes (2013) identifies three opportunity conditions mediating the impact on being fostered to create research opportunities: parentage, patronage and serendipity; and the following approach conditions: values and attitudes, lifestyle choice, effort applied, being rewarded with time and autonomy.

2 The second type - the "technician"- appreciates mainly the process of researching while the third is the one valuing foremost the "passion for research".

${ }^{3}$ Faff (2017) suggests three rules of thumb: The key papers should be (i) quite recent, (ii) published in the Top Tier journals and (iii) authored by "gurus" in the relevant field.

${ }^{4}$ The definition of the term "forced saving" is here understood in its general meaning - i.e. an involuntary saving by a consumer resulting from restrictions imposed upon expenditures, deferred income.

${ }^{5}$ The "Matthew effect" of accumulated advantage was elaborated by the sociologist R. K. Merton and refers to the biblical Gospel of Matthew (25:29): "For to every one who has will more be given, and he will have abundance; but from him who has not, even what he has will be taken away." 